\title{
PRESERVAÇÃO DO TRYPANOSOMA CRUZI EM TRIATOMÍNEOS ALIMENTADOS EM GALINHA E EM CAMUNDONGO
}

\author{
Ionizete Garcia da Silva* \& Edmo Pereira Araújo **
}

\section{RESUMO}

Estudou-se a preservação do Trypanosoma cruzi em diferentes espécies de triatomíneos, alimentados em galinha e em camundongo: Rhodnius prolixus (Stal, 1859), R. robustus (Larrousse, 1927), Triatoma brasiliensis (Neiva, 1911) e $T$. rubrovaria (Blanchard, 1843). Os triatomíneos infectaram-se com o $T$. cruzi, em camundongos com infecção aguda. Para estimar a permanencia do $T$. cruzi nos triatomíneos examinaram-se, individualmente, 20 insetos de cada espécie. Os triatomíneos permaneceram infectados pelo $T$. cruzi, tanto em camundongo quanto em galinha, ao longo de 5 meses de observação, sem definir uma alteração significativa da influência da fonte sangüinea sobre a replicação do tripanosoma.

UNITERMOS: Trypanosoma cruzi. Infecção. Triatomíneos. Tripanosomíase americana.

\section{INTRODUÇÃO}

O conhecimento sobre a preservação do Trypanosoma cruzi no triatomíneo é de grande importância para os investigadores que necessitam trabalhar com esse protozoário, por longos períodos, com o mínimo possível de alteração da sua fisiologia. Sabe-se que sucessivos repiques do T. cruzi em animais de laboratório, alteram a fisiologia desse flagelado e que a criopreservação, via de regra, é muito

Prof.do Depto. de Parasitologia do IPTSP/UFG.

" Bolsista de Iniciação Científica/CNPq.

Recebido para publicação em 25/09/95 
SILVA, I.G.; ARAÚJO, E.P. Preservação do Trypanosoma cruzi em triatomíneos alimentados em galinha e em camundongo. Rev. Pat. Trop.24 ( 2 ): 199-204, jul/dez. 1995.

onerosa. Assim, a preservação ou manutenção do $T$. cruzi em triatomíneos pode ser uma opção econômica e viável. Como o triatomíneo é o habitat natural do $T$. cruzi, parece lógico pensar que a manutenção de tripanosomas no inseto seria uma maneira equilibrada de mantê-lo, em laboratório, sem alterar-lhe a fisiologia. As espécies de triatomíneos: Rhodnius prolixus, $R$. robustus, Triatoma brasiliensis e $T$. rubrovaria já demonstraram ser boas replicádoras do $T$ cruzi 57891012

Desta forma, este trabalho teve a finalidade, não só de mostrar a permanência do $T$. cruzi quando se faz a manutenção do triatomíneo com diferentes fontes sangüíneas, como também, a possibilidade de se ter um banco de cepas de tripanosomas, preservados em triatomíneos, podendo ser alimentados tanto em camundongo quanto em galinha. Esta última, oferece mais segurança na manutenção de cepas de tripanosomas, por ser refratária à infecção chagásica.

\section{MATERIAL E MÉTODOS}

Criação - para este experimento, criaram-se triatomíneos pela técnica já estabelecida no laboratório ${ }^{3}$, numa câmara biológica, à temperatura de $25 \pm 1^{\circ} \mathrm{C}$, umidade relativa de $70 \pm 5 \%$ e fotofase de $12 \mathrm{~h}$

Inoculação - Foram inoculados, por via intra peritoneal, 20 camundongos machos albinos isogênicos, da linhagem $\mathrm{A} / \mathrm{Sn}$, com cerca de 5 semanas de vida, com $1,0 \mathrm{x}$ $10^{5}$ formas sangüíneas da cepa $Y$ de $T$. cruzi.

Contagem - No $8^{0}$ dia após a inoculação, seccionou-se a extremidade da cauda do camundongo, colheu-se $5 \mu \mathrm{l}$ de sangue com um micropipetador automático e contouse o número de tripanosomas 12

Infecção - Imediatamente após a contagem de tripanosomas, realizou-se a infecção dos triatomíneos, através da aplicação do xenodiagnóstico. Para isto, cada camundongo foi imobilizado numa tela de náilon ${ }^{5}$ e afixado aos tubos, através de elásticos, contendo um triatomíneo de cada espécie, possibilitando um permanente contato com a fonte de alimentação.

Coproscopia - As leituras do xenodiagnóstico foram realizadas aos 30, 60, 90, 120 e 150 dias após a aplicação do exame, pela técnica das dejeções espontâneas ${ }^{4}$. Esta técnica permite examinar separadamente, tanto as fezes quanto a urina, para isto é fundamental que o triatomíneo atinja a repleção total ${ }^{11}$.
SILVA, I.G.; ARAÚJO, E.P. Preservação do Trypanosoma cruzi em triatomíneos alimentados em galinha e em camundongo. Rev. Pat. Trop.24 ( 2 ): 199-204, jul/dez. 1995.

Triatomíneos - Testaram-se 4 espécies, com 20 triatomíneos de cada uma, em jejum absoluto, sendo que se usou T. brasiliensis e T. rubrovaria, 12 dias após a ecdise do $2^{\circ}$ estádio e, $R$. prolixus e $R$. robustus, 15 dias após a ecdise do $3^{\circ}$ estádio.

\section{RESULTADOS E DISCUSSÃO}

A eliminação de tripanosomas pelos triatomíneos oscilou entre as espécies e as datas dos exames. Nos primeiro, segundo e quinto meses a eliminação de $T$. cruzi foi significativamente maior $(\mathrm{P}<0,05)$ em $T$. rubrovaria, nos terceiro e quarto meses em $R$. prolixus (Fig.1). Através do $n^{\circ}$ de tripanosomas excretados, estimados em $5 \mu$ das fezes/urina ${ }^{6}$, não foi possível caracterizar o ritmo de replicação do $T$. cruzi, em nenhuma das espécies de triatomíneos utilizadas (Figs.1 e 2). A Fig.2, confirma o que ocorreu na Fig.1, a maior eliminação de tripanosomas, nos dois primeiros meses, por $T$. rubrovaria, e no terceiro mês, por $R$. prolixus. A única alteração verificada foi que, no quinto mês, $R$. robustus eliminou uma quantidade significativamente maior do que as outras espécies. Diferenças intra-específicas de suscetibilidade já foram mostradas em outras investigações

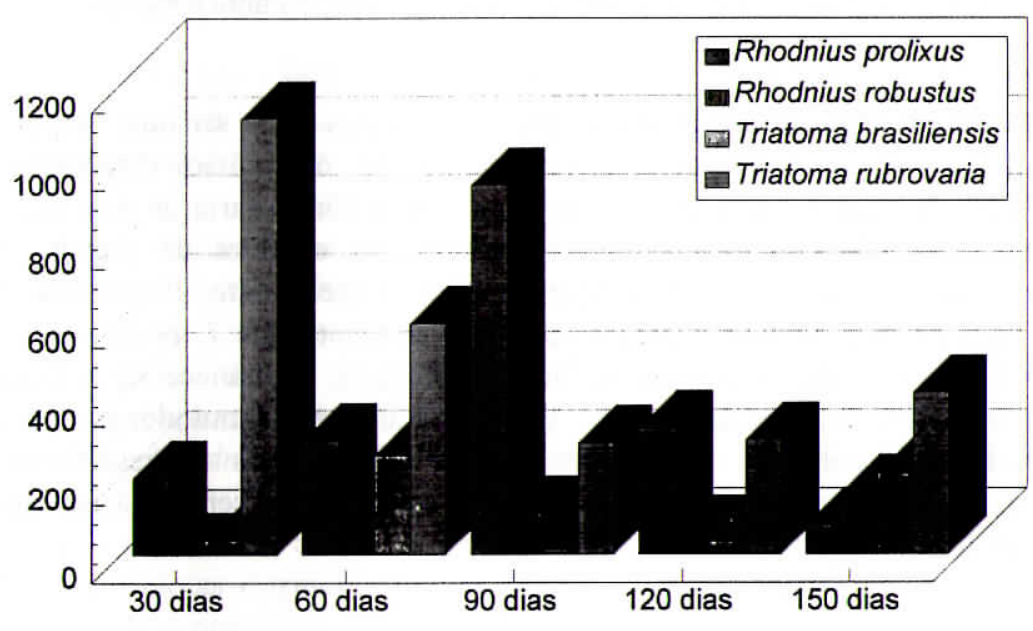

Fig.1 Número médio de Trypanosoma cruzi excretados por 4 espécies de triatomíneos, mantidos em laboratório e alimentados em camundongo, durante cinco meses. 
SILVA, I.G.; ARAÚJO, E.P. Preservação do Trypanosoma cruzi em triatomíneos alimentados em galinha e em camundongo. Rev. Pat. Trop.24 ( 2 ): 199-204, jul/dez. 1995.

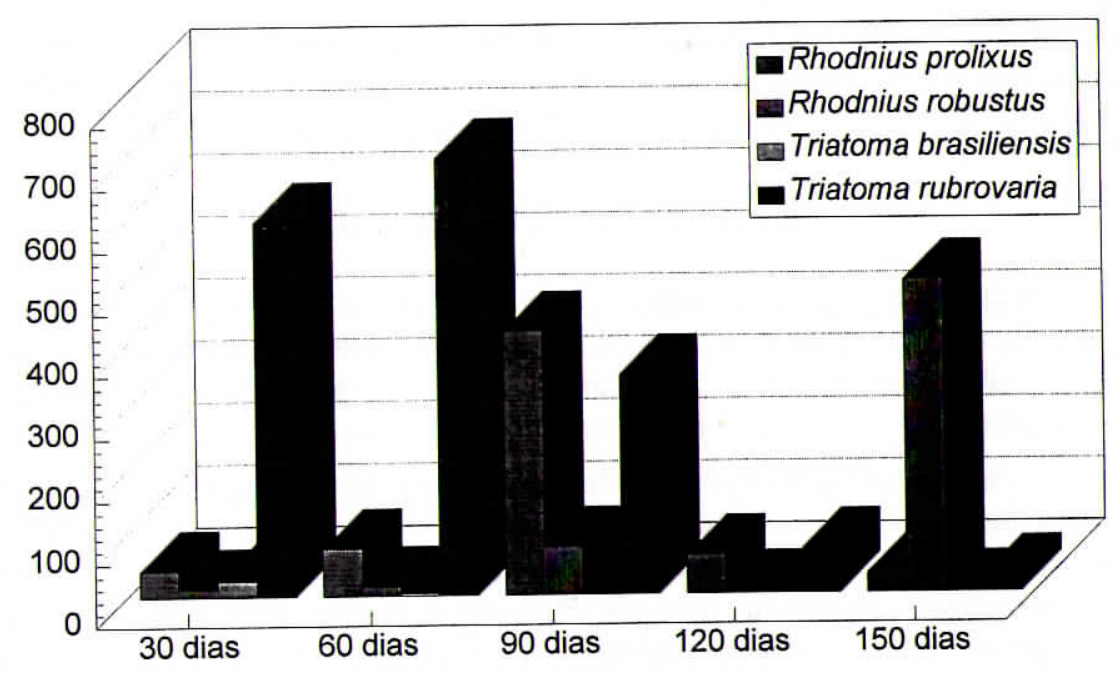

Fig.2 Número médio de Trypanosoma cruzi excretados por 4 especies de triatomíneos, mantidos em laboratório e alimentados em galinha, durante 5 meses.

A preservação de tripanosomas em triatomíneos pode ser uma opção que compatibiliza o tipo e as condições do laboratório com os recursos disponíveis. A sobrevivência de triatomíneos, em condições de laboratório, varia de seis meses a três anos, a depender da espécie e do tamanho. As espécies de grande porte sobrevivem mais tempo do que as pequenas. Neste experimento, $R$. prolixus e $R$. robustus tiveram longevidades, cerca de um ano, enquanto que $T$. brasiliensis e $T$. rubrovaria sobreviveram dois anos, ao longo dos quais, permaneceram infectados pelo T. cruzi, tanto os alimentados em galinha quanto em camundongos. Assim, pode-se utilizar a galinha, na manutenção de triatomíneos e preservação de tripanosomas, ficando disponível uma ferramenta a mais, para ser usada em bancos de cepas do $T$. cruzi.

\section{SUMMARY}

\section{Trypanosoma cruzi preservation in triatomines fed in chicken and mouse.}

The preservation of Trypanosoma cruzi in different triatomines species Rhodnius prolixus, $R$. robustus, Triatoma brasiliensis and T. rubrovaria was studied.
SILVA, I.G.; ARAÚJO, E.P. Preservação do Trypanosoma cruzi em triatomíneos alimentados em galinha e em camundongo. Rev. Pat. Trop.24 ( 2 ): 199-204, jul/dez. 1995.

The bugs were fed either on mice or chicken blood. Acutely Trypanosoma cruzi infected mice were used to infect the triatomines. In order to study the permanence of $T$. cruzi in the bug, 20 triatomines of each species were examined individually. The bugs remained infected for a period as long as 5 months, regardless of the blood source.

KEYWORDS: Trypanosoma cruzi. Infection. Triatomines. American trypanosomiasis.

\section{REFERÊNCIAS BIBLIOGRÁFICAS}

01.BRENER, Z. Contribuição ao estudo da terapêutica experimental da doença de Chagas. Tese de Livre Docência, Faculdade de Odontologia e Farmácia de Minas Gerais, Belo Horizonte, 1961. 99 p.

02.ISAC, E. Influência da heparina e do citrato de sódio no xenodiagnóstico artificial. Rev.Pat.Trop., 23:121-143, 1994.

03.SILVA, I.G. da Influência da temperatura na biologia de triatomíneos. I. Triatoma rubrovaria (Blanchard,1843) (Hemiptera, Reduviidae). Rev.Goiana Med., 31:1-37, 1985.

04.SILVA, I.G. da Nova técnica para a leitura do xenodiagnóstico. Rev.Goiana Med., 36:35-39, 1990.

05.SILVA, I.G. da \& FERREIRA, I.R. Influência da fonte sangüínea na multiplicação da cepa "Y" de Trypanosoma cruzi em Triatoma infestans (Klug, 1834) e Rhodnius neglectus Lent, 1954. Rev.Goiana Med., 36:41-48, 1990.

06.SILVA, H.H.G. da; SANTOS, A.H.; ISAC, E. \& SILVA, I.G. da Eliminação de epimastigotas e tripomastigotas através do xenodiagnóstico, pelo método das dejeções espontâneas. Rev.Pat.Trop., 23:101-106, 1994.

07.SILVA, I.G.da; LUQUETTI, A.O. \& SILVA, H.H.G. da Importância do método de obtenção das dejeções dos triatomíneos na avaliação da suscetibilidade ao Trypanosoma cruzi. Rev.Soc.Brasil.Med.Trop., 26:19-24, 1993. 
SILVA, I.G.; ARAÚJO, E.P. Preservação do Trypanosoma cruzi em triatomíneos alimentados em galinha e em camundongo. Rev. Pat. Trop.24 ( 2 ): 199-204, jul/dez. 1995.

08.SILVA, I.G. da; NAKANO, H.; SILVA, H.H.G. da \& NAKANO, R. Estudo da suscetibilidade de diferentes espécies de triatomíneos (Hemiptera, Reduviidae) ao Trypanosoma cruzi Chagas (Kinetoplastida, Trypanosomatidae). An.Soc.Entomol. Brasil, 23:495-501, 1994.

09.SILVA, I.G. da \& SALHA, L.A. Aspectos da suscetibilidade dos triatomíneos ao Trypanosoma cruzi na busca do modelo experimental. Rev.Pat.Trop., 23:93100, 1994.

10.SILVA, I.G. da; SANTOS, L.G.P. dos; NAKANO, R. \& BADAUY, R. C. Capacidade de replicação da cepa $Y$ de Trypanosoma cruzi em diferentes espécies de triatomíneos. Rev.Pat.Trop., 23:197-204, 1994.

11.SILVA, I.G. da \& SILVA, H.H.G. da. Influência da temperatura na biologia de triatomíneos. IX. Rhodnius nasutus Stal, 1859 (Hemiptera, Reduviidae). Mem.Inst. Oswaldo Cruz 84:377-382, 1989.

12.SILVA, I.G.da \& SILVA, H.H.G. da Suscetibilidade de 11 espécies de triatomíneos (Hemiptera,Reduviidae) à cepa "Y" de Trypanosoma cruzi (Kinetoplastida, Trypanosomatidae).Rev.Bras.Entomol., 37:459-463, 1993. 